\title{
Inflammatory low back pain: diagnostic and therapeutical recommendations for family doctors
}

\author{
EUGENIUSZ JÓZEF KUCHARZ¹, A-F, AGNIESZKA MASTALERZ-MIGAS², A-F,

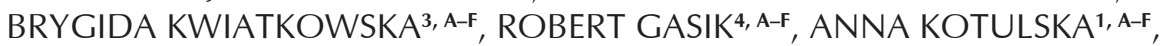 \\ JACEK KOWALCZEWSKI', A-F, TOMASZ TOMASIK', A-F
}
${ }^{1}$ Chair and Department of Internal Medicine and Rheumatology, Medical University of Silesia in Katowice
${ }^{2}$ Chair and Department of Family Medicine, Medical University of Wroclaw
${ }^{3}$ Department of Early Arthritis of the National Institute of Geriatrics, Rheumatology and Rehabilitation in Warsaw
${ }^{4}$ Department of Neuroorthopedics and Reumoorthopedics of the National Institute of Geriatrics, Rheumatology and Rehabilitation in Warsaw
${ }^{5}$ Department of Orthopaedics and Reumoorthopedics of the Postgraduate Medical Centre in Otwock
${ }^{6}$ Department of Family Medicine, Department of Internal Medicine and Gerontology, Jagiellonian
University Medical College in Krakow

A - przygotowanie projektu badania, B - zbieranie danych, C - analiza statystyczna, D - interpretacja danych, $\mathbf{E}$ - przygotowanie maszynopisu, $\mathbf{F}$ - opracowanie piśmiennictwa, $\mathbf{G}$ - pozyskanie funduszy

Summary Low back pain (LBP) or pain of the lumbo-sacral region of the vertebral column is a polyetiological clinical state. LBP is a common medical condition and has a recurrent nature. The incidence of the first LBP episode in life varies from 6.3 to $15.4 \%$ a year, while the total annual LBP incidence is estimated at up to $36 \%$. The cause of LBP can be located in the osseous structures and the joints of the vertebral column, the intervertebral discs, as well as the muscles, ligaments and nerves of the lumbo-sacral region. Commonly, the disease mechanism is complex. Differential diagnosis is an important part of the management of LBP patients due to a number of potential causes. Some forms of LBP need emergency management, and their features are known as "red flag symptoms". Such LBP forms occur at night and lack any connection with physical activity (especially in the early stage of the disease). Rapidly deteriorating LBP also needs to be considered as an emergency. Inflammatory LBP occurs in patients with inflammatory spondyloarthropathies (in $70-80 \%$ of the patients). The presented recommendations are designed to facilitate the identification of patients with inflammatory LBP. They also describe rules of referring to a rheumatologist, as well as focus on the cooperation of a family doctor and a rheumatologist in the treatment of these patients. In most patients LBP is the first symptom of inflammatory spondyloartropathy. The classification criteria of inflammatory LBP are as follows: 1) onset at the age below 40; 2) insidious onset; 3) an improvement after physical exercise; 4) the lack of improvement after rest; 5) pain at night with improvement after getting up from bed. Non-pharmacological (kinesiotherapy, patient education) and pharmacological methods (non-steroidal anti-inflammatory drugs, TNF-alpha blockers) are used in the management of patients with inflammatory spondyloartropathy.

Key words: low back pain, red flag symptoms, inflammatory spondyloarthropaties

Fam Med Prim Care Rev 2016; 18(3): 399-407

\section{List of abbreviations:}

CT - computed tomography

RM - magnetic resonance imaging

AS - ankylosing spondylitis
ESSG - European Spondyloarthropathy Study Group

ASAS - Assessment in Ankylosing Spondylitis International Society

NSAID - non-steroidal anti-inflammatory drugs

IPP - proton pump inhibitor

\section{Background}

The study is the result of the team work of specialists of several medical disciplines, and it is dedicated to the problem of lumbosacral pain or low back pain. The pain has diverse aetiology which is not always possible to be accurately established. It can be a symptom of very serious conditions requiring immediate medical attention, and has a chronic and relapsing character, deteriorating the quality of life, constituting a threat to life, and requiring a complex analysis of diagnostics and therapy. Undoubtedly, it represents a frequent and serious problem in medical practice.

The aim of the study was to create a guide for family doctors, to facilitate making initial diagnosis, to identify a group of patients with inflammatory lumbosacral pain, and above all to select patients requiring immediate specialist intervention. These patients need rapid referral to a rheumatologist, and so far experience shows that they get there too late for specialist treatment. Being a small proportion of all patients with low back pain, they are not properly diagnosed because the inflammatory nature of the pain often escapes the mind of the family doctor. Paying attention to the differences in inflammatory back pain which may be a harbinger of inflammatory spondyloarthropathies is the message of this study.

The last two decades have been a period of the development of new therapeutic methods used in patients with diseases such as ankylosing spondylitis, psoriatic arthritis, 
reactive arthritis and spondyloarthropathies associated with non-specific enteritis. The introduction of new drugs for clinical practice in patients diagnosed relatively early allows us to avoid the development of serious injuries and to extend life. The achievement of these objectives requires early diagnosis of inflammatory low back pain and referral of the patient to a specialist for further diagnosis and treatment.

\section{General characteristics of low back pain}

The term "lumbar-sacral pain of the spine" is a descriptive term which characterizes the clinical condition. It is not the name of the disease entity, but a polyetiological syndrome. The definition is not precise because it includes symptoms associated with diseases of paraspinal and spinal structures. Therefore, other terms are used, including "lumbar pain", "pain of the lower back area", "back pain" or "low back pain". In the study the expressions "lumbarsacral pain" and "back pain" are used interchangeably, as terms with the same meaning. Despite the semantic differences mentioned above, these Polish phrases correspond to the English expression "low back pain" and refer to one of the most common clinical conditions, which is a significant problem both in medical and social terms.

A primary determinant of pain in the lumbar part of the spine is the place of occurrence. The pain may be due to pathological lesions in the bony structures and joints of the spine, as well as in the intervertebral discs, muscles, tendons and nerves of the lumbar-sacral region. Most often, we encounter a complex mechanism of pain, in which lesions causing pain are located in different types of structures constituting the discussed region of the body, and may be either primary or secondary to other changes (e.g. lesions of the bone or intervertebral discs may cause changes in the nerves) [1].

Low back pain, as a syndrome caused by different causes, has a diverse clinical picture. The onset may be acute and associated with excessive or abnormal loads (overload, weight lift, sudden twist of the body), it can have a subacute onset (appearing some time after overload) or appear insidiously, in a chronic way. The duration of pain is also different. Acute pain lasts less than 6 weeks, subacute - 6-12 weeks, and chronic - over 12 weeks. Four etiological groups of low back pain are distinguished:

- pain growing under the influence of pathological changes in the course of degenerative disease and injuries (including those caused by tension or injury, "strain", contraction of the muscles, herniated nucleus pulposus, herniated disc, pressure on the spinal cord, degenerative arthritis of the spine, compression fracture of the vertebra),

- $\quad$ pain associated with neoplastic changes - primary or metastatic,

- infectious pain (osteoarthritis, including tuberculosis and metastatic abscess),

- inflammatory pain.

This division applies to aetiology, whereas in clinical practice we use a more detailed classification which facilitates making the initial diagnosis (see: Diagnostic management). The study is limited to the latter type of low back pain, i.e. inflammatory and other states are only mentioned as elements to be considered in differential diagnosis.

\section{Epidemiology of low back pain}

Low back pain is the most common complaint of people worldwide. The heterogeneity of ailments, the polyetiological character, as well as different criteria and methods of pain detection cause the considerable diversity of available epidemiological data.
The incidence of the first episode of low back pain is $6.3-15.4 \%$ a year. The pain occurs in a significant number of patients as early as in early adulthood (up to 34 years). Symptoms tend to recur, and the annual incidence of low back pain (first or renewed) is up to $36 \%$ of the population. It has a tendency to increase with age and intensify in the fifth and sixth decades of life. The pain subsides, and remissions are observed in $54-90 \%$ of patients a year. The probability of relapse is estimated at $20-80 \%$ a year [2].

Morbidity is considerable and amounts to an average of $38.1 \%$, although in some studies it is as high as $82.5 \%$. Assuming lower morbidity, we can accept that the disease affects every second or third adult in the general population [2]. There are significant geographic differences in the prevalence of low back pain. Higher prevalence is found, among others, in Denmark, Great Britain and Ukraine, and is lower in China and Finland. However, for many countries there are no data available [3]. In 2016 the results of a large study conducted in Portugal indicated the prevalence of low back pain in $26.4 \%$ of the entire adult population of the country. The prevalence was slightly higher in women $(29.6 \%)$ than in men $(22.8 \%)$. It intensified gradually until the age of 35 years and maintained a high level until the age of 70 years [4].

Factors that have an influence on the occurrence of back pain include age (3-6 decades of life), and female gender, although this is not supported by all studies [2]. Socio-economic factors are important, and include low education, poor family income, difficulties in access to medical care, and psychological factors, including depression and sleep disorders. Tension, stress and physical strain at work are not without significance [5].

Low back pain is not just a problem of the quality of life. This is also the problem of absenteeism and increased mortality. It is estimated that in patients with low back pain the risk of premature death in the total population is increased about two times [6].

Inflammatory pain is much less known. The epidemiology of spondyloarthropathies is discussed further below. The adverse effect of smoking on the occurrence and severity of inflammatory pain is relevant. The risk factors for inflammatory pain include lack of education, high activity of inflammation at the beginning of clinically overt disease, and disclosure in middle-age or childhood [6].

\section{Diagnostic management}

Because of the large number of patients presenting to a family doctor with low back pain, it is necessary to efficiently make an initial diagnosis. The causes of back pain can be:

- degenerative changes - mainly in patients over 60 years - they can affect intervertebral joints, intervertebral discs and vertebral bodies as such (worsening of symptoms, repeated recurrences of pain),

- injuries - prolapsed intervertebral disc, vertebral fracture, damage to the ligaments and/or muscles (usually sudden onset),

- inflammation - inflammatory spondyloarthropathies,

- infections - tuberculosis, septic inflammation of the disc,

- tumours - primary and metastatic,

- $\quad$ inborn changes - stenosis, spondylolisthesis, scoliosis, transitional vertebrae,

- diseases of internal organs - kidney stones, pancreatitis, aortic aneurysm, intestinal diseases.

A family doctor in his/her practice has the following instruments that help to make an initial diagnosis: medical history taking, physical examination, determination of the concentration of C-reactive protein (CRP), erythrocyte sedimentation rate (ESR), and lumbar-sacral spine radiographs.

When differentiating causes of low back pain, medical history should take into consideration the patient's age, pain 
radiation, and the time of appearance during the day. It is important to answer the questions: does pain persist after exercise, or is there morning stiffness? Positive answers to these questions suggest inflammatory pain. Low back inflammatory pain usually affects people under 40 years of age, has an insidious onset, occurs at night (often in the second half of the night; it may cause awakening of the patient) and may occur alternately in the buttocks. It decreases after exercise and does not disappear after rest; morning stiffness of this area remains for more than 30 minutes.

In order to distinguish the causes of the pain, the physical examination should include stretch tests of the nerve roots. The positive result of Lasčgue's test and the examination carried out in a sitting position, with simultaneous straightening of the knee joint, dorsiflexion of the foot and head tilt, are simple methods indicating nerve root compression. Disturbances of superficial sensation (in the corresponding dermatomes) also indicate damage/compression of the nerve root. Neurological disorders, such as foot drop and urinary and faecal incontinence, indicate the non-inflammatory aetiology of low back pain, and are referred to as "red flag symptoms" that require urgent and broadened specialist diagnostics.

If the origin of pain is unclear, it is desirable to have abdominal ultrasonography in order to evaluate the aorta (aneurysm), pancreatic lesions (inflammation, tumour) and the kidneys (calculosis, cancer, pyelonephritis).

If the medical history reveals an injury and low back pain (communication injuries, fall from a height, in the elderly), we must perform radiographs in two projections: anterior-posterior and lateral, or refer the patient to a hospital emergency department.

\section{Differential diagnosis}

Low back pain is a non-specific symptom applicable to many diseases. One of the divisions differentiates the etiological factors of low back pain into three groups: factors associated with the structures of the musculoskeletal system, neurogenic, and paraspinal [7]. Often, correct diagnosis is difficult as different causes of low back pain overlap. For this reason, it is particularly important to perform a thorough differential diagnosis, especially in those with longer lasting pain.

\section{Pain syndromes resulting from the presence of musculoskeletal system lesions}

- Lumbar intervertebral discs are responsible for approximately $40 \%$ of low back pain. Damage to the intervertebral disc occurs mostly in osteoarthritis as a result of biochemical changes. They cause damage to the structure of the discs, leading to back pain. Inflammation of the intervertebral disc or an injury can also cause pain. Inflammation of the intervertebral disc may be bacterial or non-infectious. Bacterial iatrogenic inflammation of the intervertebral disc is extremely rare and occurs in approximately $1-3 \%$ of previously surgically treated patients [8].

- Sacroiliac joints are responsible for approximately $18-30 \%$ of cases of chronic low back pain. Making a diagnosis in patients with diseases of the sacroiliac joints causes difficulties due to the non-specific clinical picture, which can suggest abnormalities of other structures, such as intervertebral discs, spinal joints or hip joints. Pathological changes of the sacroiliac joints causing low back pain include osteoarthritis, joint instability and bacterial or non-infectious inflammation, including that associated with spondyloarthropathies [7].

- Inter-process joints of the spine - their changes cause symptoms in $15-31 \%$ of patients with low back pain. They include degenerative-proliferative changes of the joints and damage caused by trauma [7].
- Vertebrae - anomalies within the vertebral bodies are important etiological factors of low back pain. These usually include vertebral fracture and spondylolisthesis.

o fractures of the vertebral body - cause discomfort in $2.9 \%$ of patients with low back pain. They can be divided into traumatic and pathological fractures. Traumatic fracture most often occurs as a result of a fall from a height (approx. 40\%) and traffic accidents (approx. 25\%) [9]. The second type are pathological fractures, usually in the course of osteoporosis, infection or neoplastic process.

o spondylolisthesis - a dislocation forward of the vertebrae with the whole section of the vertebrae lying above in relation to the vertebra situated below. The following are types of spondylolisthesis:

- Type I (dysplastic) - congenital, usually at the level of L5 and S1,

- $\quad$ Type II (isthmus) - may be caused by inborn changes, for example spondylolysis,

- Type III (degenerative) - develops in the course of degenerative disease of the spine,

- Type IV (traumatic) - as a result of a traumatic injury to the spinal structure responsible for its stability,

- Type V (pathological) - usually caused by an infectious or neoplastic change in the structure of the bone.

- Paraspinal soft tissues - abnormalities of the muscles and ligaments of the spine are one of the most common causes of low back pain. The immediate causes often include increased tension and strained muscle, degeneration and damage to the ligaments of the spine, piriformis muscle syndrome and secondary soft tissue changes associated with instability of the lumbar spine. Physical examination, CT scan or magnetic resonance imaging are helpful in making a diagnosis.

\section{Neurogenic pain syndromes}

In clinical practice they are most commonly considered together with low back pain resulting from the presence of musculoskeletal system lesions. The symptoms caused by damage to the nervous structures of the spine include sensory loss symptoms, muscle paresis and disturbance of bowel control. Neurogenic claudication, which develops in the course of spinal canal stenosis, is a typical example of the syndrome which combines a lot of the elements mentioned above. Typical symptoms of neurogenic claudication are sensory symptoms and muscle weakness of the lower limbs which grow along with effort. These symptoms usually disappear in a sitting position.

\section{Low back pain in the course of other diseases}

Low back pain is frequently accompanied by rheumatic diseases, most commonly: rheumatoid arthritis, ankylosing spondylitis and psoriatic arthritis.

- $\quad$ Rheumatoid arthritis - the disease typically affects the small joints, but can attack any of the synovial joints; it is manifested by pain, stiffness and impaired range of motion in the spine. Most lesions are located in the cervical spine. In these patients low back pain caused by an underlying disease is rare [10] and is most often the result of treatment complications, e.g. fractures of the vertebral body due to steroid osteoporosis. The progressive destruction of the joints, including inter-process joints, can sometimes cause compression of the neural structures and symptoms of damage to the neural structures of the spinal canal.

- Axial spondyloarthropathies - ankylosing spondylitis (AS), axial psoriatic arthritis (PsA), reactive arthritis $(\operatorname{ReA})$, axial spondyloarthropathies accompanying in- 
flammatory diseases of the intestines, undifferentiated axial spondyloarthropathies - in the early stage of the disease we observe non-specific low back pain, uni- or bilateral, often radiating to the groin or buttocks. Next, pain can appear in the thoracic spine, which is often perceived by the patient as girdle pain. In the later stage of the disease, the entire spine is immobilized and the symptoms caused by compression of the spinal nervous structures overlap on the clinical picture of the disease. In axial psoriatic arthritis the initial symptoms are the same as in AS. Inflammatory changes in the sacroiliac joints are usually one-sided, which is felt by the patient as low back pain on the right or left side. Total spinal fusion is not encountered in this disease [10].

- Other rheumatic diseases - low back pain can also occur in diseases such as polymyalgia rheumatica, with pain accompanied by morning stiffness of the pelvic girdle, sarcoidosis of the musculoskeletal system, and Behcet's disease. Therefore, they should also be included in differential diagnosis.

In patients seeking medical attention due to chronic low back pain, diseases of the urinary, reproductive and digestive systems can also cause complaints. In the course of these diseases, pain projects. The results of physical examination and additional tests in this group of patients do not confirm the connection between pain and pathological changes of the spine.

\section{Emergencies and red flag symptoms}

Low back pain syndromes are most often caused by changes associated with osteoarthritis. Making the correct diagnosis and identifying causes is not a problem in the dominant proportion of patients and is based on medical history, physical examination and imaging studies.

In the group of patients with low back pain, individuals whose pain can be a symptom of another serious illness should be subjected to a detailed diagnosis. A typical feature of this type of pain is the nocturnal nature and (often at the beginning of the disease) no association with physical activity. Low back pain with increasing intensity and associated with physical activity must also be diagnosed promptly. This kind of pain is not defined as a red flag symptom.

Table 1. The symptoms associated with low back pain indicating the urgent need to broaden diagnosis, the so-called red flag symptoms

\section{Red flag symptoms indicating unusual causes of back pain}

Pain that occurs for the first time over the age of 50 years or under 20 years

- Exacerbation of pain at night

- Intensification of pain in the supine position and the lack of a clear connection with physical exertion

- Diagnosed cancer

- The use of immunosuppressive drugs

- Finding in the physical examination the following neurological deficits:

- $\quad$ Sphincter control disorders, muscle paralysis, superficial sensation disorders, especially located in the perineum

Special attention should be paid to patients with the first episode of low back pain at the age over 50 years and below 20 years, as well as people with cancer and/or patients treated with immunosuppressive drugs. While taking a medical history we should ask these patients about weight loss and elevated body temperature.

The last group of symptoms associated with low back pain, which indicate the need for urgent medical action, is based on neurological examination. This group includes: superficial sensation disturbances, abnormal bowel and bladder control, and muscle paresis (Tables 1,2).

\begin{tabular}{|l|l|}
\hline \multicolumn{2}{|l|}{ Table 2. Diseases which manifest selected red flag symptoms } \\
\hline Red flag symptoms & $\begin{array}{l}\text { Diseases associated with red } \\
\text { flag symptoms }\end{array}$ \\
\hline $\begin{array}{l}\text { Low back pain accompanied } \\
\text { by increased body tempera- } \\
\text { ture and weight loss }\end{array}$ & $\begin{array}{l}\text { Bacterial inflammation } \\
\text { of the intervertebral disc, } \\
\text { non-bacterial inflammation } \\
\text { of the intervertebral disc, } \\
\text { spinal abscess, tuberculosis, } \\
\text { brucellosis, fungal infec- } \\
\text { tions, granulomatosis with } \\
\text { vasculitis (formerly known as } \\
\text { Wegener's granulomatosis) }\end{array}$ \\
\hline Nocturnal low back pain & $\begin{array}{l}\text { Cancer, vascular malforma- } \\
\text { tions, syringomyelia }\end{array}$ \\
\hline $\begin{array}{l}\text { Low back pain accompa- } \\
\text { nied by a feeling of morning } \\
\text { stiffness }\end{array}$ & $\begin{array}{l}\text { Spinal canal stenosis with } \\
\text { the symptoms of neurogenic } \\
\text { claudication }\end{array}$ \\
\hline
\end{tabular}

\section{Prevention of the transformation of acute pain into chronic pain}

The prevention of low back pain, especially primary prevention, is a difficult task faced by a family doctor. There are few well-documented studies on the effectiveness of interventions. Prevention includes the promotion of healthy lifestyle among patients and encouraging them to take part in physical activity, including exercises strengthening the abdominal muscles and the back. It is recommended to maintain healthy body weight and correct posture, to use the proper technique of lifting heavy objects, and ergonomics in the workplace.

After the exclusion of a specific disease that might be the cause of the most common ailments, a family doctor diagnoses nonspecific low back pain (without specific causative agents, $>95 \%$ of cases). It is self-limited, although it often recurs. It becomes chronic in approximately 3-10\% of patients. A family doctor can counteract this condition (secondary prevention) and thus prevent the development of disability, reduction of the patient's social burden, inability to work, and the consequent work loss.

It is therefore important to identify patients at high risk of conversion of acute pain into chronic pain. Biopsychosocial predictors, also known as "yellow flags”, are helpful in this regard [11]. They include: depression, personality disorders, fears and beliefs about pain (pain perception as unpredictable and impossible to control), worries, the lack of satisfaction and excessive work demands, family problems, medical care which enhances the conviction of a serious disease of the spine.

It also turns out that unnecessary diagnostic tests independently increase the risk of pain conversion [12]. Hence, conventional radiographs, CT and $\mathrm{MRI}$, which are important for suspected serious abnormalities, for example axial spondyloarthropathies, tumours, infections, fractures, and cauda equina syndrome, are not recommended in patients with non-specific low back pain. The disclosure of irrelevant changes in the structure of the intervertebral discs, vertebral bodies and processes, which also occur in people with no symptoms, causes adverse effects in patients. This confirms in them a sense of disease, increases the sensation of pain, and causes more frequent reporting on the visit and more aggressive, risky and complicated treatment [13, 14]. Of course, the expansion of diagnosis is required when there is no improvement after several weeks of treatment, or new symptoms appear which suggest a specific cause of pain.

Early interventions that can reverse the adverse effects leading patients with low back pain to disability are: avoiding lengthy sick leaves, encouraging early return to daily activities, stressing that "movement is healthy" and does 
not lead to further damage to the spine [15], and avoiding bed rest [16]. As in other chronic diseases, a doctor should educate patients and provide psychological support for them and their families. We should include the patient in the process of decision-making and responsibility for health. There may be a need to discuss unrealistic expectations, e.g. complete resolution of symptoms and no recurrence. In some cases, it is necessary to refer the patient to a psychologist, psychiatrist or occupational health professional. The preventive measures, however, should not use any kind of belts, orthoses, special mattresses or shoe insoles.

The proper care of patients with low back pain, and the prevention of the onset of chronic pain requires from a family doctor a lot of experience, increased attention and consideration of the biopsychosocial model of care. On the one hand, we should avoid unnecessary referrals for additional tests and specialist consultations; on the other hand, we must not overlook threatening conditions.

\section{Inflammatory back pain}

Inflammatory back pain is a complex of symptoms included in the classification criteria. It belongs to the group of autoimmune inflammatory diseases known as inflammatory spondyloarthropathies. Inflammatory back pain occurs in $5-10 \%$ of patients, depending on the type of population and classification criteria used [17]. In inflammatory spondarthropathies, back pain occurs in $70-80 \%$ of patients [18]. In most patients inflammatory back pain is one of the first symptoms of axial spondyloarthropathy, and may precede other typical clinical signs of the disease by many years.

Mechanical back pain occurs in $60-80 \%$ of the adult population [19]. Because of the very high incidence of chronic mechanical back pain in the general population in 1977, Calin presented the first classification criteria of inflammatory back pain. They were modified in 1991 by the ESSG (European Spondyloarthropathy Study Group) and in 2006 and 2009 in Berlin by the ASAS (Assessment in Ankylosing Spondylitis International Society) (Table 3) [20].

\section{General characteristics of spondyloarthropathies}

\section{Definition and epidemiology}

Spondyloarthropathies are a group of chronic, inflammatory autoimmune diseases, characterized by:

- changes in the axial skeleton,

- changes in the peripheral joints,

- extra-articular symptoms.
Spondyloarthropathies include:

- ankylosing spondylitis,

- psoriatic arthritis,

- reactive arthritis,

- $\quad$ arthritis associated with non-specific inflammatory bowel diseases (ulcerative colitis, Crohn's disease),

- youthful spondyloarthropathy,

- undifferentiated spondyloarthropathy.

Based on the dominance of the musculoskeletal system symptoms, spondyloarthropathies are divided into [20, 21]:

- axial (affecting mainly the axial skeleton)

- $\quad$ radiographic (with visible radiographic features of inflammation in the sacroiliac joints and/ /or spine)

- non-radiographic (without visible inflammatory changes in the sacroiliac joints and/or spine in traditional radiography);

- $\quad$ peripheral (affecting mainly the peripheral joints).

Radiographic and non-radiographic axis spondyloarthropies have similar clinical pictures and responses to treatment. In the majority of patients, non-radiographic axis spondyloarthropy transforms into radiographic spondyloarthropy, and after about 10 years of the disease $60 \%$ of patients are diagnosed with ankylosing spondylitis with typical inflammatory lesions in radiological test of the sacroiliac joints.

Factors predisposing patients to the rapid progression of non-radiographic spondyloarthropy to AS are:

- being male,

- young age at onset,

- increased concentration of C-reactive protein,

- the absence of peripheral arthritis,

- uveitis,

- $\quad$ the presence of HLA-B27 antigen [21].

Likewise, severe inflammatory lesions found in sacroiliac MRI and visualized as bone marrow oedema indicate the more rapid progression of non-radiographic spondyloarthropy to AS, which is observed in as many as $60 \%$ of patients after two years of the disease $[22,23]$.

Spondyloarthropathies have common characteristics, i.e. clinical symptoms, response to treatment, and genetic predisposition (the higher prevalence of HLA B27 antigen). In adults spondyloarthropathies occur in 1-2.5\% of the population $[24,25]$. In spondarthropathies, in addition to the typical changes in the motor system, extra-articular symptoms are also characteristic [22]:

- uveitis (6.7-23.3\% of patients),

- $\quad$ psoriasis (13.3-16.2\% of patients),

- non-specific inflammatory bowel disease (2.9-10\% of patients).

In 2009 the ASAS created classification criteria for axial spondyloarthropathy (Fig. 1).

\begin{tabular}{|c|c|c|c|}
\hline Calin (1977) & ESSG (1991) & Berlin (2006) & ASAS (2009) \\
\hline $\begin{array}{l}\text { 1. Onset < } 40 \text { years of age } \\
\text { 2. Duration of back pain } \\
\text { > } 3 \text { months } \\
\text { 3. Insidious onset } \\
\text { 4. Accompanying morning } \\
\text { stiffness } \\
\text { 5. Improvement after } \\
\text { exercise }\end{array}$ & $\begin{array}{l}\text { Current or past history of pain } \\
\text { in the lumbar, thoracic or } \\
\text { cervical area together with at } \\
\text { least } 4 \text { of the following: } \\
\text { 1. Onset < } 45 \text { years of age } \\
\text { 2. Insidious onset } \\
\text { 3. Improvement after } \\
\text { exercise } \\
\text { 4. Accompanying morn- } \\
\text { ing stiffness } \\
\text { 5. Duration of at least } \\
3 \text { months }\end{array}$ & $\begin{array}{l}\text { For patients }<50 \text { years of age } \\
\text { 1. Morning stiffness }>30 \\
\text { minutes } \\
\text { 2. Improvement after exer- } \\
\text { cise but not rest } \\
\text { 3. Awakening due to pain } \\
\text { in the second half of the } \\
\text { night } \\
\text { 4. Alternate sore buttocks }\end{array}$ & $\begin{array}{l}\text { 1. Onset <40 years of age } \\
\text { 2. Insidious onset } \\
\text { 3. Improvement after } \\
\text { exercise } \\
\text { 4. No improvement after } \\
\text { rest } \\
\text { 5. Pain at night (with im- } \\
\text { provement after getting } \\
\text { up) }\end{array}$ \\
\hline $\begin{array}{l}\text { met } 4 \text { out of } 5 \\
\text { sensitivity }-91.2 \% \\
\text { specificity }-50 \%\end{array}$ & $\begin{array}{l}\text { met } 4 \text { out of } 5 \\
\text { sensitivity }-62.5 \% \\
\text { specificity }-81.1 \%\end{array}$ & $\begin{array}{l}\text { met } 2 \text { out of } 4 \\
\text { sensitivity }-75.8 \% \\
\text { specificity }-83.3 \%\end{array}$ & $\begin{array}{l}\text { met } 4 \text { out of } 5 \\
\text { sensitivity } 79.6 \% \\
\text { specificity } 72.4 \%\end{array}$ \\
\hline
\end{tabular}




\section{Back pain $\geq 3$ months with an onset $<45$ years of age}

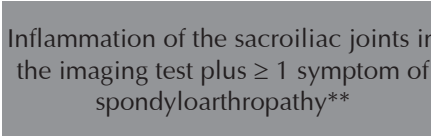

Inflammation of the sacroiliac joints in the imaging test:

- $\quad$ active inflammation shown in tomography, nuclea magnetic resonance strongly suggesting inflammation of the sacroiliac joints associated with spondyloarthropathy;

- $\quad$ certain inflammation of the sacroiliac joints diagnosed based on radiological criteria, the modified New York criteria for AS diagnosis, i.e. radiologically confirmed bilateral inflammation 2-4 degree or unilateral 3-4 degree

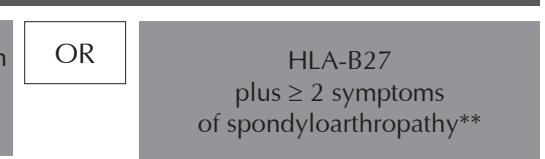

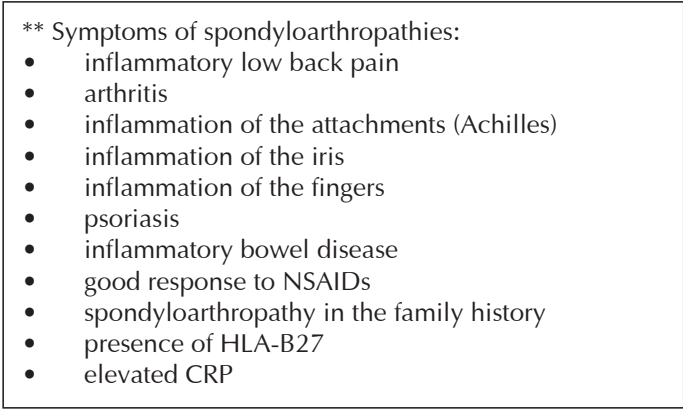

Sensitivity: $82.9 \%$, specificity $84.4 \%$

Only imaging: sensitivity $66.2 \%$, specificity $97.3 \%$

Only clinical: sensitivity $56.6 \%$, specificity $83.3 \%$

Figure 1. Classification criteria for axial spondyloarthropathy by ASAS

* A potential X-ray is recommended to assess the sacroiliac joints.

\subsection{Diagnosis}

The preliminary diagnosis of spondyloarthropathy can be made based on medical history taking. A questionnaire completed by the patient may be helpful (Table 4). At least 4 "yes" answers give a high probability of inflammatory back pain in the course of axial spondyloarthropathy.

The scheme of diagnostics recommended to a GP is shown in Figure 2.

\begin{tabular}{|c|c|c|c|}
\hline & Question & Yes & No \\
\hline 1. & Did your back pain start before the age of 45 years? & & \\
\hline 2. & Did your back pain start insidiously, and has it lasted $>3$ months? & & \\
\hline 3. & Does your back pain decrease after movement and exercise? & & \\
\hline 4. & Does your back pain decrease after rest? & & \\
\hline 5. & Does your back pain occur in the second half of the night and disappear after getting out of bed and stretching? & & \\
\hline 6. & Is the pain accompanied by morning stiffness of the spine $>30$ minutes? & & \\
\hline 7. & Is there alternate buttock pain? & & \\
\hline 8. & Is there any improvement with non-steroidal anti-inflammatory drugs? & & \\
\hline
\end{tabular}

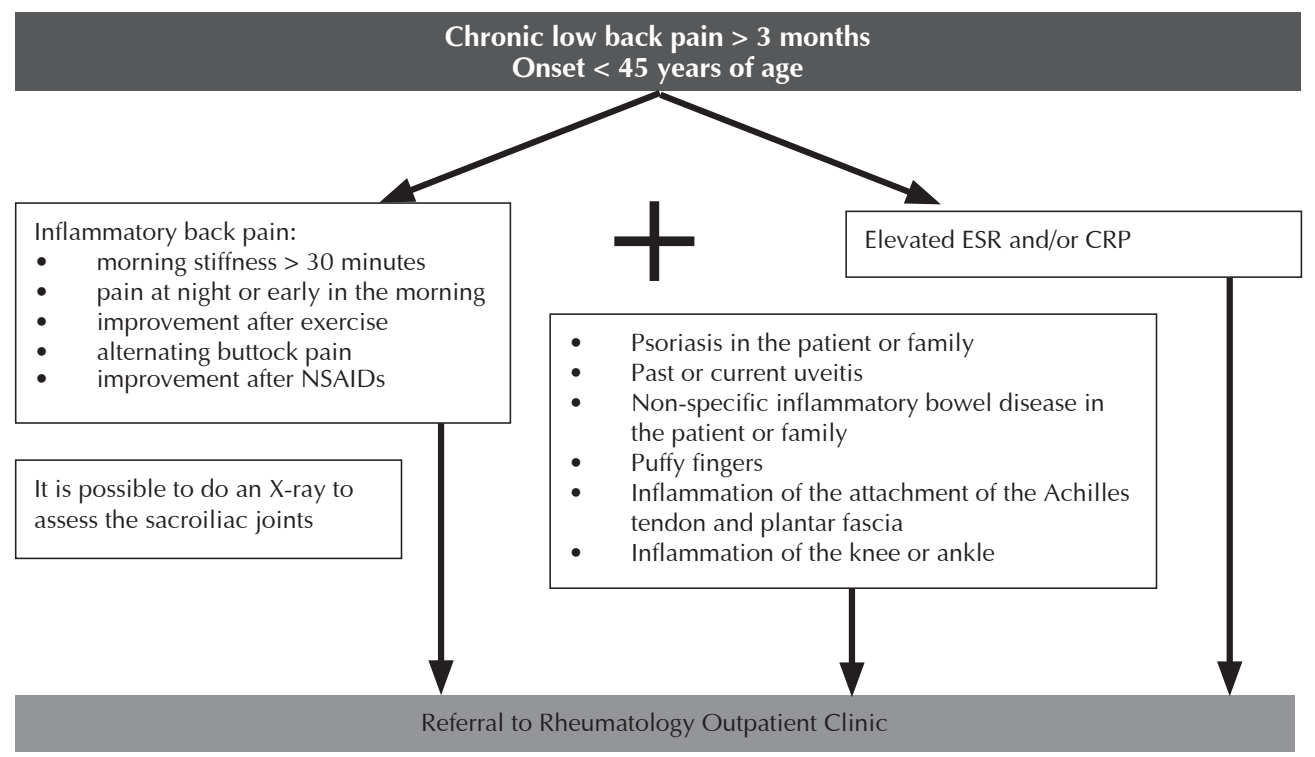

Figure 2. The scheme of diagnostic procedures in the suspicion of spondyloarthropathy 


\section{Treatment of axial spondyloarthropathies}

The treatment of axial spondyloarthropathies is both non-pharmacological and pharmacological. It is recommended to individualize the treatment depending on current symptoms, the activity of spinal arthritis, the progression of the disease, the degree of disability and cooperation with the patient. It is necessary to assess the overall condition of the patient, concomitant diseases (especially inflammatory bowel diseases) and medicines.

Patient education plays an important role in the non-pharmacological treatment: explanation of the nature of the disease, its length, expected prognosis, therapeutic options, the role of cooperation between the patient and the doctor, as well as the importance of physiotherapy conducted under the guidance of a physiotherapist. Regular exercise performed at home, which the patient should learn and continue to the end of life, helps to maintain efficiency and thus prevent disabilities [28].

NSAIDs are the first-line therapy in the pharmacological treatment, especially in AS patients who suffer from pain and stiffness. If high disease activity persists, NSAIDs should be used chronically, but taking into account possible side effects, especially gastrointestinal and renal, and the increased risk of cardiovascular events. Treatment with high doses of these drugs is the most effective. Protectively, IPP or NSAIDs from the coxib group should be used in patients with increased risk of gastrointestinal complications. There are ongoing studies aiming to demonstrate the efficacy of NSAIDs in the prevention of the new bone formation and the creation of syndesmophytes. The confirmation of such an action would justify the use of these drugs, even in patients in whom pain and stiffness have subsided.

There is no research on the effectiveness of paracetamol and opioids in patients with axial spondyloarthropathies. These drugs are administered when there are contraindications to the use of NSAIDs or they are not well tolerated $[28,29]$.

There are no data showing the effectiveness of the systemic administration of glucocorticoids in axial spondarthropathies. These drugs are used only locally by injection into the joints and periarticular tissues. There is also no evidence for the effectiveness of synthetic disease-modifying drugs, such as methotrexate, leflunomide or sulfosalazine in the treatment of patients with axial inflammatory spondyloarthropathies.

If there is no improvement after applying the treatment described above, and high activity of the disease continues, it is advisable to use biological drugs like TNF- $\alpha$ inhibitors. According to the ASAS recommendations, the following criteria should be met in the assessment made by a rheumatologist to administer this class of medicines:

- high activity of the disease maintained for a period of four weeks or more,

- $\quad$ BASDAI index (Bath Ankylosing Spondylitis Disease Activity Index) $\geq 4$,

- treatment failure by at least two NSAIDs, used separately for four weeks, at the maximum recommended or tolerated doses.

There is no requirement for the prior use of disease-modifying drugs since, as mentioned above, they are not effective in the axial character of the disease.

The following inhibitors of TNF- $\alpha$ are used in axial spondarthropathies: adalimumab, cetrolizumab, pegol, etanercept, infliximab and golimumab. There are no significant differences in the effectiveness of different inhibitors of TNF- $\alpha$, but when choosing the drug a rheumatologist should take into account the coexistence of inflammatory bowel diseases, and the patient's preferences as to the manner and frequency of administration of the biological agent. The exposure to TB infection (present or past) also has an influence on the selection of an inhibitor of TNF- $\alpha$. Biologic drugs are currently the most effective drugs in severe and active forms of axial spondyloarthropathies [29].
In Poland, biological treatment is carried out in selected rheumatological centres, of which there are now more than 100. Patients are usually referred to these centres by rheumatologists. Biological treatment does not exclude care performed by a family doctor for the patient, especially when other diseases coexist. Care should be exercised with the cooperation of specialists (a rheumatologist from the centre which deals with biological treatment, a family doctor or a rheumatologist from a specialist outpatient clinic which treats the patient).

Surgeries, such as hip arthroplasty or operations on significant deformities of the spine may be considered in the treatment of advanced changes leading to disability. The aim of comprehensive non-pharmacological and pharmacological treatment of patients with axial spondyloarthropy is to eliminate pain, and to restore and maintain the proper posture and mobility of the spine as much as possible, and thus maintain the independence of the patient and his/her functioning in society.

\section{The principles of spondyloarthropathy therapy in general practice}

Non-steroidal anti-inflammatory drugs (NSAIDs) are the first-line drugs in the treatment of spondyloarthropathies. It is recommended to take them chronically, at the maximum dose tolerated by the patient. NSAIDs inhibit the disease progression and in some patients show high efficacy.

The choice of NSAIDs should be individual in terms of safety, and the effects on the digestive and/or cardiovascular system should be taken into account. If there are no gastrointestinal and cardiovascular loads, any of the NSAIDs can be administered without a proton pump inhibitor (PPI). If there are gastrointestinal loads, we should preferentially apply cycloxygenases- 2 inhibitors (e.g. Meloxicam) together with IPP or selective cycloxygenases-2 inhibitors (e.g. Celecoxib) with or without IPP. If there are cardiovascular loads, naproxen should be used [30].

It is also important to recommend early rehabilitation exercises, preferably unloaded. We can use intra-articular glucocorticoids in the sacroiliac joints or peripheral joints with effusion.

\section{The rules of referring the patient to a rheumatology outpatient clinic}

Each patient who is suspected of spondyloarthropy based on the criteria described in the earlier parts of this publication should be referred to a rheumatologist. Because of the need for early diagnosis confirmation in this group, and the very long waiting time for specialist consultation, a referral should be endorsed with the word "urgent". If Centres for Early Diagnosis Rheumatology are created, it will be possible to refer patients there. The codes of the International Statistical Classification of Diseases and Related Health Problems ICD-10, which should be considered when writing a referral, are: M45 (ankylosing spondylitis) and M46 (other inflammatory diseases of the spine).

A family doctor ought to receive full information about the diagnosis, implemented treatment, and management in case of specific situations, such as an unexpected infection, side effects, or proceedings in the case of surgery, pregnancy and immunization [31].

In most cases there are no indications to refer the patient with suspected spondyloarthropathy to a rheumatology department. Doing so may be considered in cases of severe pain, significantly increased laboratory indicators of inflammation, and the existence of contraindications to the NSAID treatment. A rheumatologist refers the patient to a stationary care facility in cases of diagnostic difficulties, multiple co- 
existing diseases, treatment complications, or the need for comprehensive rehabilitation.

\section{The cooperation between a family doctor and a rheumatologist}

The cooperation between a family doctor and a rheumatologist should occur on several levels:

- diagnosis of inflammatory back pain,

- the effective treatment of back pain,

- cooperation during the continuation of recommended treatment,

- observation and possible treatment of adverse effects of drugs,

- infectious disease prevention (including vaccination).

\section{Summary}

The role of a family doctor in the early diagnosis of inflammatory back pain is extremely important, because in most cases his/her diagnostic vigilance and knowledge of the symptoms typical of this pain determine the fate of the patient - the possibility of a full diagnosis and effective therapy under the supervision of a specialist. It is also crucial to carry out a preliminary differential diagnosis, and to avoid the situation when as a result of "vigilance" a GP refers all young patients with lumbar-sacral pain to a rheumatologic outpatient clinic.

Given the long waiting time for rheumatologist consultation, a family doctor can initiate the first-line therapy (NSAIDs) and non-pharmacological treatment. A family doctor should also participate in the long-term treatment of the patient, even if it is carried out in a specialist centre. This is due to the fact that she/he knows the co-morbidities of the patient, and frequent visits to a GP are more available than those to a specialist centre (detection of possible adverse reactions to drugs, drug interactions when using medication for another disease). She/he also has a better knowledge of the non-medical conditions of the patient, which can, among other things, influence compliance.

Source of funding: The meeting of the expert group was financed by Abbvie, but it had no influence on the content of the study. Conflict of interest: The authors declare no conflict of interests.

\section{References}

1. Styczyński T. Regionalne zespoły bólowe. In: Zimmermann-Gorska I, ed. Postępy reumatologii klinicznej. Warszawa: Wydawnictwo Lekarskie PZWL; 2014: 397-411.

2. Hoy D, Brooks P, Blyth F, et al. The epidemiology of low back pain. Best Pract Res Clin Rheumatol 2010; 24(6): $769-781$.

3. Majid K, Truumees E. Epidemiology and natural history of low back pain. Semin Spine Surg 2008; 20: 87-92.

4. Branco JC, Rodrigues AM, Gouveia N, et al. Prevalence of rheumatic and musculoskeletal diseases and their impact on healthrelated quality of life, physical function and mental health in Portugal: results from EpiRheumaPt - a national health survey. RMD Open 2016; 2: e000166.

5. Shmagel A, Foley R, Ibrahim H. Epidemiology of chronic low back pain in US adults: National Health and Nutrition Examination Survey 2009-2010. Arthritis Care Res 2016; Mar 18, doi: 10.1002/acr.22890 [in press].

6. Lukas C, Dougados M, Combe B. Factors associated with a bad functional prognosis in early inflammatory back pain: results from the DESIR cohort. RMD Open 2015; 2: e000204.

7. Amirdelfan K, McRoberts P, Deer TR. The differential diagnosis of low back pain: a primer on the evolving paradigm. Neuromodulation 2014; 17(Suppl. 2): 11-17.

8. DePalma MJ, Ketchum JM, Saullo T. What is the cause of chronic low back pain and does age play a role? Pain Med 2011; 12(2): 224-233.

9. Hu R, Mustard CA, Burns C. Epidemiology of incident spinal fracture in a general population. Spine 1996; 21(4): $492-499$.

10. Neva $\mathrm{MH}$, Häkkinen $\mathrm{A}$, Isomäki $\mathrm{P}$, et al. Chronic back pain in patients with rheumatoid arthritis and in a control population: prevalence and disability - a 5-year follow-up. Rheumatology 2011; 50(9): 1635-1639, doi: 10.1093/rheumatology/ker173.

11. Melloh M, Elfering A, Egli Presland C, et al. Identification of prognostic factors for chronicity in patients with low back pain: a review of screening instruments. Int Orthop 2009; 33(2): 301-313.

12. Dagenais S, Tricco AC, Haldeman S. Synthesis of recommendations for the assessment and management of low back pain from recent clinical practice guidelines. Spine 2010; 10(6): 514-529.

13. Webster BS, Bauer AZ, Choi Y, et al. latrogenic consequences of early magnetic resonance imaging in acute, work-related, disabling low back pain. Spine 2013; 38(22): 1939-1946.

14. Webster BS, Choi Y, Bauer AZ, et al. The cascade of medical services and associated longitudinal costs due to nonadherent magnetic resonance imaging for low back pain. Spine 2014; 39(17): 1433-1440.

15. Monnin D, Courvoisier DS, Genevay S. Modifying beliefs about back pain: a pilot study among healthcare professionals. Patient Educ Couns 2016; 99(4): 665-670.

16. Salzberg LD, Manusov EG. Management options for patients with chronic back pain without an etiology. Health Serv Insights 2013; 28: 33-38.

17. Weisman $\mathrm{MH}$, Witter JP, Reveille JD. The prevalence of inflammatory back pain: population-based estimates from the US National Health and Nutrition Examination Survey, 2009-2010. Ann Rheum Dis 2013; 72(3): 369-373.

18. Heuft-Dorenbosch L, Landewé R, Weijers R, et al. Performance of various criteria sets in patients with inflammatory back pain of short duration; the Maastricht early spondyloarthritis clinic. Ann Rheum Dis 2007; 66(1): 92-98.

19. Kramza J, Kucharz E.J. Mechaniczny ból krzyża - rozpoznanie i leczenie. Świat Med Farm 2013; 8(147): 24-31.

20. Reveille JD, Weisman MH. The epidemiology of back pain, axial spondyloarthritis and HLA-B27 in the United States. Am J Med Sci 2013; 345(6): 431-436.

21. Kucharz EJ. Reumatologia i angiologia. In: Duława J, ed. Vademecum medycyny wewnętrznej. Warszawa: Wydawnictwo Lekarskie PZWL; 2015: 396-433.

22. Kucharz EJ. Spondyloartropatie seronegatywne. In: Steciwko A, ed. Medycyna rodzinna - co nowego?. Wrocław: Cornetis; 2010; 1: 224-228.

23. Poddubnyy $\mathrm{D}$, Rudwaleit $\mathrm{M}$, Haibel $\mathrm{H}$, et al. Rates and predictors of radiographic sacroiliitis progression over 2 years in patients with axial spondyloarthritis. Ann Rheum Dis 2011; 70(8): 1369-1374.

24. van Tubergen A. The changing clinical picture and epidemiology of spondyloarthritis. Nature Reviews Rheumatology 2015; 11: 110-118. 
25. Akkoc N. Are spondyloarthropathies as common as rheumatoid arthritis worldwide? Curr Rheumatol Rep 2008; 10(5): 371-378 .

26. Stolwijk C, Boonen A, van Tubergen A, et al. Epidemiology of spondyloarthritis. Rheum Dis Clin North Am 2012; 38(3): 441-476.

27. Kwiatkowska B. Wczesne diagnozowanie zapaleń stawów. Reumatol Geriatr Rehabil 2015; 1(1): 13-17.

28. Szechiński J, Kucharz EJ. Łuszczycowe zapalenie stawów. In: Gajewski P, ed. Interna Szczeklika. Kraków: Medycyna Praktyczna; 2015: 1905-1910.

29. Taurog JD, Chhabra A, Colbert RA. Ankylosing spondylitis and axial spondyloarthritis. N Engl J Med 2016; 374(26): $2563-2574$.

30. Kroon FP, van der Burg LR, Ramiro S, et al. Nonsteroidal antiinflammatory drugs for axial spondyloarthritis: a Cochrane review. J Rheumatol 2016; 43(3): 607-617.

31. van den Berg R, van der Heijde DM. How should we diagnose spondyloarthritis according to the ASAS classification criteria: a guide for practicing physicians. Pol Arch Med Wew 2010; 120(11): 452-457.

Address for correspondence:

Agnieszka Mastalerz-Migas, MD, PhD, Assoc. Prof.

Katedra i Zakład Medycyny Rodzinnej UM

ul. Syrokomli 1

51-141 Wrocław

Polska

Tel.: +48 71 325-51-26

E-mail: agnieszka.migas@gmail.com

Received: 15.08.2016

Revised: 21.08.2016

Accepted: 21.08.2016 